\title{
SOSÁGUA-MC: um aplicativo colaborativo para promoção do consumo consciente de água e apoio à educação ambiental
}

\author{
Danilo P. de Oliveira ${ }^{1}$, Vitor C. de Carvalho, Rafael D. Araújo ${ }^{1}$ \\ ${ }^{1}$ Faculdade de Computação \\ Universidade Federal de Uberlândia (UFU) \\ Campus Monte Carmelo - MG \\ danilopxl@ufu.br, vitorcdecarvalho@gmail.com, rafael.araujo@ufu.br
}

\begin{abstract}
With environmental education in focus, it is important to create mechanisms and technological tools to support the teaching and learning process of this theme in schools. In particular, solutions have been created to promote awareness and preservation of local and global water resources. This paper presents a prototype of an Android application to promote conscious consumption of water through anonymous complaints carried out in a collaborative and categorized way, and with the possibility of displaying related media news as a learning resource for elementary school students.
\end{abstract}

Resumo. Com questões relacionadas à educação ambiental em foco, é importante criar mecanismos e ferramentas tecnológicas que auxiliem o processo de ensino e aprendizagem dessa temática nas escolas. Em especial, soluções têm sido criadas para promover a conscientização e a preservação dos recursos hídricos locais e globais. Este artigo apresenta um protótipo de um aplicativo Android para promoção do consumo consciente de água, por meio de denúncias anônimas efetuadas de forma colaborativa e categorizadas, e com a possibilidade de vinculação de notícias da mídia relacionadas e contextualizadas como recurso de aprendizagem para estudantes do ensino fundamental.

\section{Introdução}

Questões relacionadas ao meio ambiente alcançam segmentos da esfera social, política e econômica, exigindo reflexões acerca da utilização dos recursos da natureza. Em especial, os recursos hídricos do planeta estão se tornando cada vez mais escassos não só devido à poluição dos rios e mananciais, mas também devido ao consumo irresponsável e sem fundamentação sustentável no desenvolvimento econômico. Além da importância da água do ponto de vista biológico, ela também é essencial para diversas atividades produtivas, como atividades da agricultura, da indústria, domésticas e até mesmo recreacionais. Apesar da água ser um recurso abundante no planeta terra, nem toda essa disponibilidade é própria para o consumo (chamada de água potável).

Dessa forma, diversas pesquisas têm sido conduzidas com o intuito de preservar mananciais e criar mecanismos que minimizem a utilização desnecessária da água bem como sua reutilização. Complementarmente, torna-se necessário criar ações que visam a redução do seu desperdício por meio de consumo consciente na sociedade como um todo. Especialistas alertam que poderá haver um déficit hídrico no mundo, caso o consumo continue da mesma forma [Silva et al. 2017, Nelson 2017, André et al. 2015]. 
VIII Congresso Brasileiro de Informática na Educação (CBIE 2019)

Anais dos Workshops do VIII Congresso Brasileiro de Informática na Educação (WCBIE 2019)

Ainda, o objetivo 6 do desenvolvimento sustentável definido no Relatório de Síntese sobre Água e Saneamento de 2018 da Organização das Nações Unidas reconhece que o desenvolvimento social e a prosperidade econômica dependem do gerenciamento sustentável dos recursos de água doce e dos ecossistemas [ONU 2018]. Assim, é importante que a sociedade se conscientize e aprenda utilizar a água da forma correta, evitando seu desperdício no seu dia-a-dia. No Brasil, o índice de perdas na distribuição (Indicador IN049 do Sistema Nacional de Informações sobre Saneamento - SNIS) foi de 38,3\% em 2017 [SNIS 2017].

Especialmente em uma região cuja principal atividade econômica é o agronegócio, como a região da cidade de Monte Carmelo/MG, torna-se ainda mais importante a utilização consciente desse recurso para evitar sua escassez. Toda a região sofre anualmente com episódios de falta e/ou racionamento de água. Em agosto do ano de 2017, por exemplo, as reservas de água do município apresentaram defasagem e escassez em seu volume [Monte Carmelo News 2017], o que exigiu medidas por parte das instituições competentes para reduzir o gasto de água até que a situação se normalizasse novamente. Essa situação é recorrente durante o período de estiagem na região. Apesar dos índices de perdas na distribuição de água na área urbana da cidade ter diminuído levemente nos últimos anos (37\% para 35\%) [Rodrigues et al. 2019], ainda representa um problema bastante considerável.

Como todo ser vivo de nosso planeta, nós, seres humanos dependemos dos recursos do meio ambiente para termos nosso provento. Porém, nesse processo, as sobras são devolvidas [Brondani and Henzel 2010], causando poluição e muitas vezes atrapalhando nosso desenvolvimento. Surgiu, então, a necessidade da inclusão de um bom ensino ambiental nas escolas [Porto 1998] para que as crianças e jovens estudantes sejam ensinados e se conscientizem com os problemas atuais e urgentes, entre eles, o problema da escassez da água, abordado por este trabalho.

Tanto no website do Departamento Municipal de Água e Esgoto (DMAE) de Monte Carmelo quanto da Agência Nacional de Águas (ANA) existe um formulário para efetuar denúncias anônimas e identificadas sobre o gasto inconsciente de água e fiscalização dos recursos hídricos [DEMAE nd, ANA nd], no entanto, diferenças podem ser apontadas, como a inexistência de um mapa para facilitar a marcação do local da denúncia, denúncias não categorizadas e impossibilidade de visualizar as denúncias efetuadas e resolvidas. Além disso, aplicativos que proporcionam apenas a funcionalidade de efetuar denúncias não estão preparados para serem utilizados como ferramenta de apoio ao ensino.

Porém, segundo dados do Comitê Gestor da Internet no Brasil (CGI.br), o acesso à internet via telefone celular tem crescido a cada ano e já supera o acesso feito por computadores domésticos em alguns cenários [CGI.br 2018]. Assim, a disponibilidade de uma aplicação para dispositivos móveis, em especial, smartphones, pode facilitar o acesso às formas de denúncia já disponíveis, além de fornecer uma ferramenta de divulgação de informações para esse contexto bem como uma ferramenta mais atrativa que poderia ser utilizada em escolas de ensino fundamental como ferramenta de suporte ao ensino e para promoção da conscientização acerca do tema.

Sendo assim, o aplicativo proposto contempla funcionalidades colaborativas para 
VIII Congresso Brasileiro de Informática na Educação (CBIE 2019)

Anais dos Workshops do VIII Congresso Brasileiro de Informática na Educação (WCBIE 2019)

realização de denúncias do desperdício de água na comunidade local, bem como recursos que permitem a inserção de notícias relacionadas ao consumo consciente de água como recursos didáticos externos que podem ser utilizados em sala de aula como apoio à educação ambiental no ensino fundamental. A possibilidade de realização de denúncias anônimas colaborativamente se torna uma ferramenta que contribui tanto para o desenvolvimento de uma conscientização para uso adequado dos recursos hídricos, que é fundamental para o exercício de cidadania plena nos dias atuais, quanto para exercitar a proatividade dos estudantes. A utilização de notícias como fontes externas relacionadas às denúncias pode ser utilizada para promover a busca e o compartilhamento de conhecimento tanto entre os estudantes quanto entre seus familiares como membros da comunidade que estão inseridos.

\section{Desenvolvimento}

A partir de uma ação pedagógica interna da gestão da Escola Estadual Melo Viana, na cidade de Monte Carmelo/MG, surgiu a necessidade da construção de um aplicativo para smartphones para ser utilizado como ferramenta de conscientização do consumo racional de água na cidade. Assim, dada a demanda identificada, foram levantados os requisitos funcionais (RF) e não-funcionais (RNF) necessários para a construção do aplicativo junto à direção da escola, sendo eles:

- RF1: o aplicativo deve permitir que os alunos informem possíveis constatações de desperdício de água na cidade por meio de denúncias anônimas, de forma colaborativa;

- RF2: as denúncias devem possuir categorias;

- RF3: deve ser possível visualizar todas as denúncias realizadas (pendentes e resolvidas);

- RF4: qualquer usuário pode alterar o status de uma denúncia para "Resolvida";

- RF5: o status de uma denúncia resolvida pode ser confirmado por outros usuários;

- RF6: os administradores poderão cadastrar links de notícias externas relacionadas com as categorias das denúncias para ações de conscientização;

- RNF1: o aplicativo deve ser construído para smartphones Android;

- RNF2: as denúncias devem ser anônimas, não permitindo a identificação dos usuários;

- RNF3: não deve existir nenhum custo para os alunos utilizarem o aplicativo;

- RNF4: devem ser registrados logs das interações dos usuários;

- RNF5: as tecnologias utilizadas devem ser gratuitas.

Com os requisitos, foram realizadas reuniões para modelagem de dados e projeto do software. Como um dos requisitos do aplicativo é a construção colaborativa de denúncias de desperdício de água, definiu-se utilizar a linguagem de programação PHP para construção de uma aplicação Web para processamento das requisições do aplicativo Android. $\mathrm{O}$ aplicativo mobile foi desenvolvido utilizando a linguagem de programação Java juntamente com o Android Software Development Kit (SDK), com compatibilidade para versões superiores a versão 4.4 (KitKat) do Android, e o armazenamento local de dados acontece por meio da biblioteca $S Q L i e^{1}$, que permite a manipulação de dados SQL (Structured Query Language, ou Linguagem de Consulta Estruturada), sem executar um Sistema de Gerenciamento de Banco de Dados (SGBD) separadamente.

\footnotetext{
${ }^{1}$ https://www.sqlite.org/about.html
} 
VIII Congresso Brasileiro de Informática na Educação (CBIE 2019)

Anais dos Workshops do VIII Congresso Brasileiro de Informática na Educação (WCBIE 2019)

O aplicativo Android foi compilado utilizando o Ambiente de Desenvolvimento Integrado (IDE) Android Studio², ferramenta produzida e distribuída pela Google, sendo, em suma, uma aplicação utilizada no processo de desenvolvimento de aplicativos para a plataforma Android. Ainda, o código-fonte foi armazenado na plataforma de controle de versão GitHub ${ }^{3}$. Os dados são armazenados e recuperados por meio de chamadas de serviços Web, implementados na linguagem PHP, que são responsáveis por acessar a base de dados armazenadas em um servidor remoto.

A fim de facilitar a indicação do local da ocorrência a ser cadastrada, foi utilizada API (do inglês, Application Programming Interface) do Google Maps ${ }^{4}$ para que, assim que identificado um problema relacionado ao mal uso dos recursos hídricos, o aplicativo possa identificar o local atual onde o usuário se encontra por meio da localização do sensor GPS (Global Positioning System) para, então, cadastrar uma denúncia naquela posição e exibição em um mapa de ocorrências.

A Figura 1 mostra um protótipo de baixa fidelidade utilizado para esboçar o layout da aplicação. A tela inicial contém apenas botões para acesso às funcionalidades relacionadas às denúncias (nova denúncia, visualização de denúncias pendentes e visualização de denúncias resolvidas). Apesar de serem poucas funcionalidades, não houve nenhum teste de usabilidade.

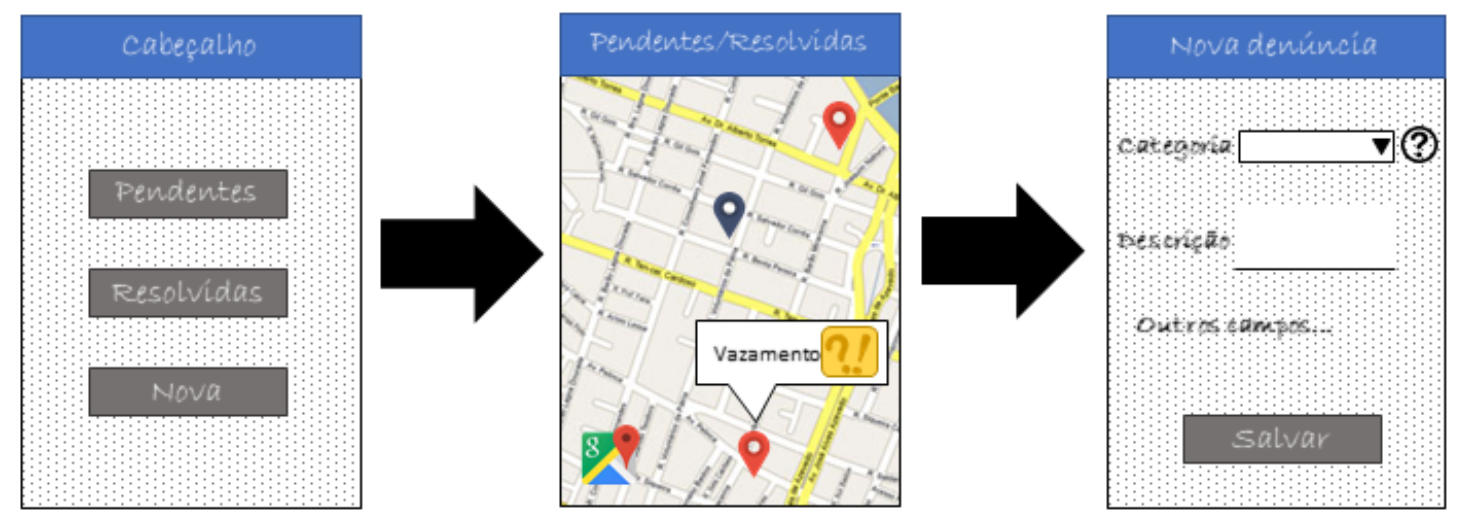

Figura 1. Wireframe criado para esboço das principais telas.

\section{Apresentação do software}

O aplicativo deve ser instalado em smartphones com o Sistema Operacional Android, versão 4.4 (KitKat) ou superior. Sua distribuição é gratuita com Licença Creative Commons Attribution-NonCommercial 4.0 International ${ }^{5}$. Não é necessário realizar nenhum cadastro para utilização do aplicativo.

A tela principal do aplicativo possui apenas três botões: um para cadastrar uma nova denúncia, um para visualizar as denúncias pendentes e um outro para visualizar as denúncias resolvidas, como mostrado na Figura 2(a).

\footnotetext{
${ }^{2}$ https://developer.android.com/studio

${ }^{3}$ https://github.com

${ }^{4}$ https://cloud.google.com/maps-platform

${ }^{5}$ CC BY-NC 4.0: https: / / creativecommons.org/ licenses/by-nc/4 . 0
} 
VIII Congresso Brasileiro de Informática na Educação (CBIE 2019)

Anais dos Workshops do VIII Congresso Brasileiro de Informática na Educação (WCBIE 2019)

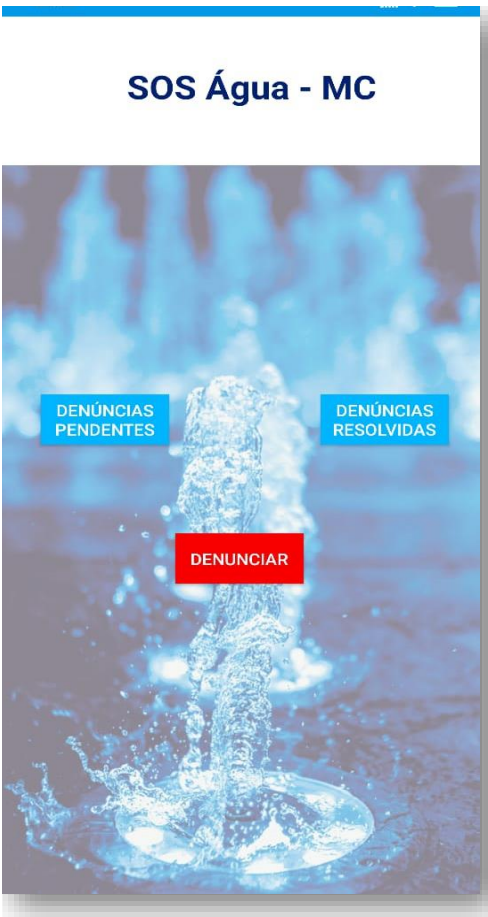

(a)

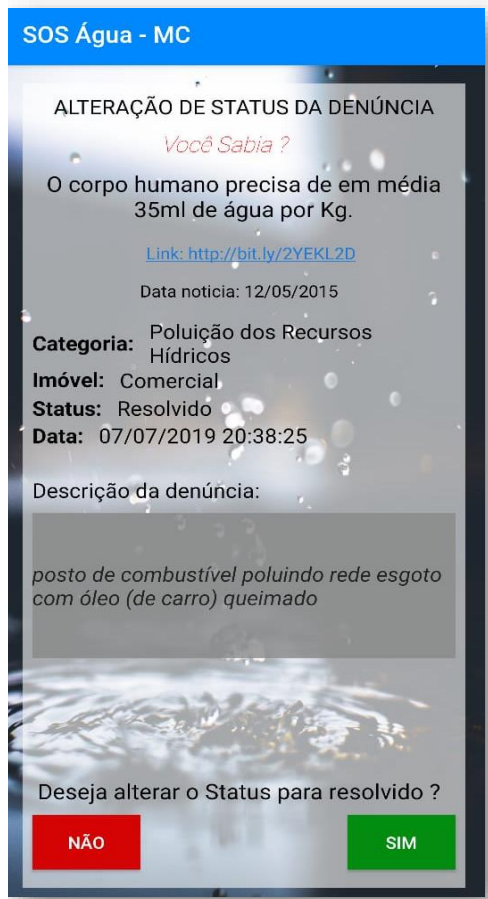

(d)

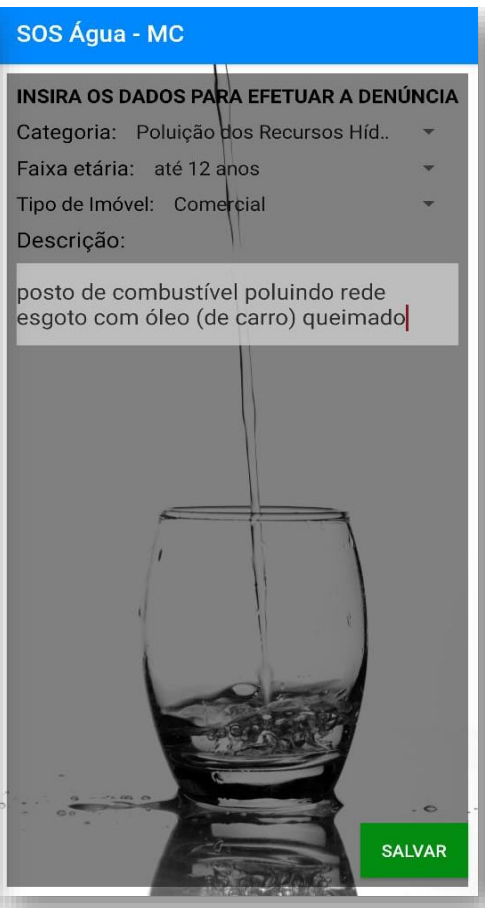

(b)

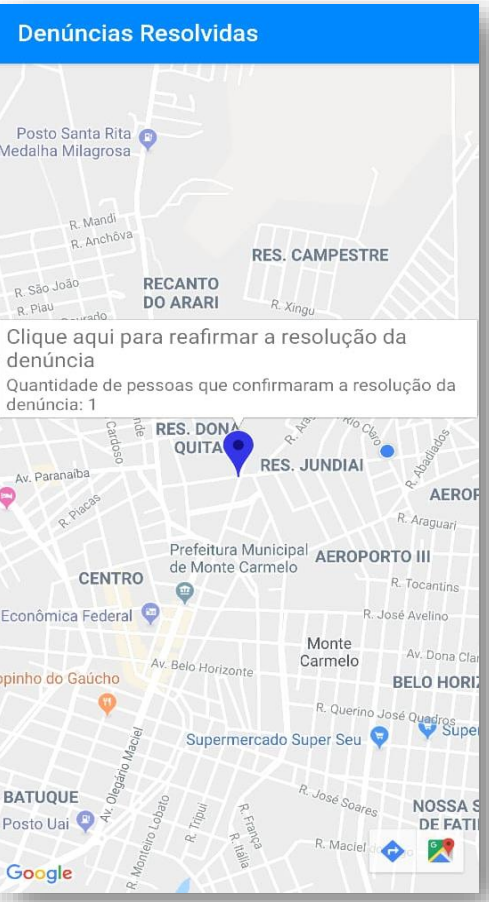

(e)

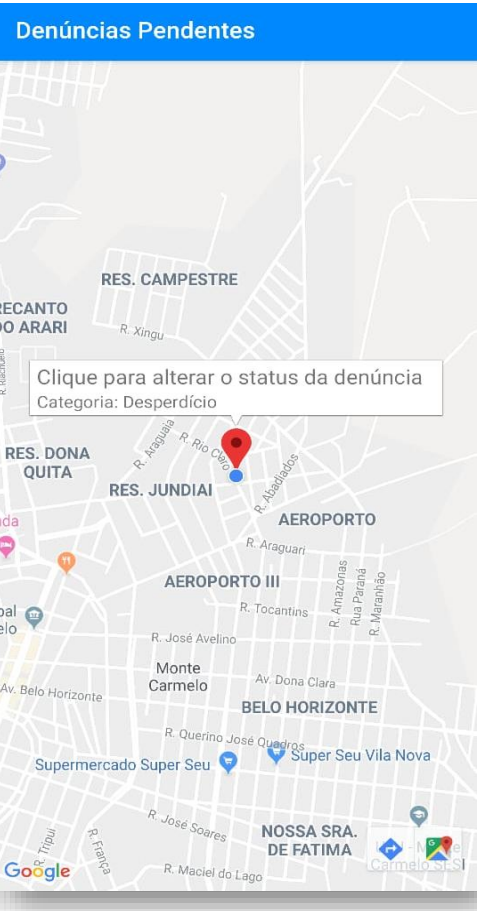

(c)

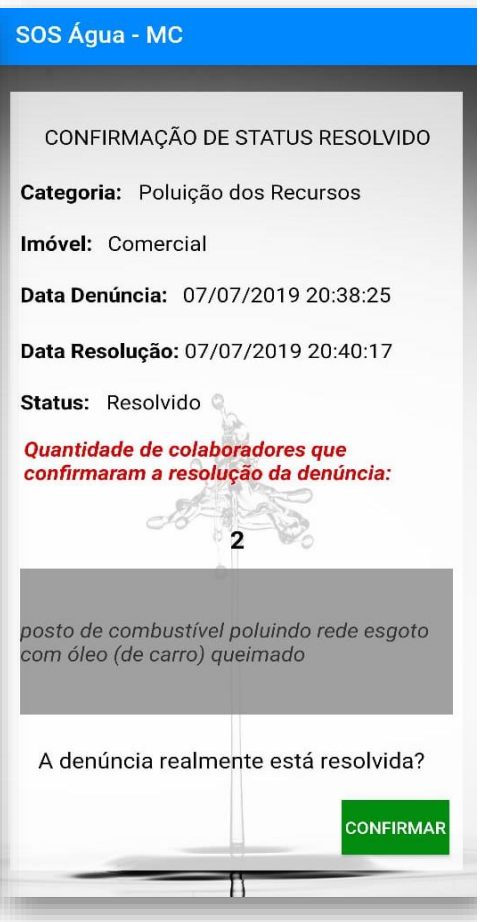

(f)

Figura 2. (a) Tela inicial; (b) Nova denúncia; (c) Denúncias pendentes; (d) Alteração de status da denúncia; (e) Denúncias resolvidas; (f) Confirmação de status da denúncia. 
VIII Congresso Brasileiro de Informática na Educação (CBIE 2019)

Anais dos Workshops do VIII Congresso Brasileiro de Informática na Educação (WCBIE 2019)

Na tela de cadastro de nova denúncia, Figura 2(b), existem algumas categorias de denúncias e outros informações, para que o usuário possa ser mais exato de sua denúncia. As categorias de denúncia são divididas em: Vazamento, Desperdício, Captação Irregular, Poluição dos Recursos Hídricos, Perfuração de Poço Artesiano Irregular e Outros, para os casos onde nenhuma das categorias anteriores possam se encaixar.

Ainda na tela de denúncia, o usuário deve informar qual a sua faixa etária, apenas para estatísticas futuras, e o tipo do imóvel que está sendo denunciado, separado em Comercial, Residencial, Industrial e Outros. Além de conter também um campo de descrição, para que o usuário possa informar melhor, com suas palavras, o que está denunciando.

Uma vez que o usuário cadastra a denúncia, ela não possui mais relação com seu usuário por causa do anonimato. Se ele se direcionar para a tela de denúncias pendentes, caso haja alguma denúncia cadastrada, será possível visualizá-la(s) por meio de marcadores no mapa, como apresentado na Figura 2(c). Clicando no ícone do marcador, é possível ver os detalhes da denúncia que foi cadastrada e, ainda, mudar seu status, caso a denúncia tenha sido resolvida, conforme mostrado na Figura 2(d).

Ainda na tela de detalhes da denúncia pendente, além das informações fornecidas pelo usuário que cadastrou a denúncia, foi inserido também uma sessão de curiosidades sobre a água, que trará notícias e informações a fim de informar mais aos usuários sobre este recurso natural tão valioso.

Uma vez que a denúncia tenha sido marcada como resolvida por ele mesmo, ou outro usuário, a mesma aparece na tela de denúncias resolvidas, apresentada na Figura 2(e). Os marcadores indicativos das denúncias são azuis e indicam as denúncias que algum usuário já marcou como resolvidas. Porém, para dar maior credibilidade, ao visualizar os detalhes da denúncia resolvida, como mostrado na Figura 2(f), qualquer outro usuário pode confirmar que a denúncia já foi resolvida, incrementando um contador para auxiliar os usuários a verificar a veracidade desta informação.

\subsection{Componente de aprendizagem}

O processo de aprendizagem envolve a assimilação de diferentes formas de conhecimento, desde o mais simples onde a criança começa a aprender com atividades sensoriais, como tocar e manipular os brinquedos, cheirar objetos, experimentar comidas, até processos mais complexos, como escolher uma profissão ou se relacionar umas com as outras [Libâneo 1994]. De acordo com a teoria de Paulo Freire, as práticas pedagógicas devem ser contextualizadas para que se faça avançar o conhecimento de forma crítica tendo o professor como mediador desse processo [Freire 1979].

Dessa forma, a partir das ocorrências cadastradas colaborativamente pelos estudantes, os professores podem vincular notícias relacionadas com a categoria da denúncia, de forma a contextualizar o ocorrido com fatos que já aconteceram anteriormente e virou notícia jornalística. Uma vez cadastrada, o link para a notícia e data de publicação aparecerá na tela de "Alteração de status da denúncia" que contém todos os dados da ocorrência e a possibilidade de informar que aquela denúncia já foi resolvida, como mostrado na Figura 3. O cadastro dos links para as notícias acontece manualmente por meio de uma interface Web, cujo acesso é exclusivo do professor. 
VIII Congresso Brasileiro de Informática na Educação (CBIE 2019)

Anais dos Workshops do VIII Congresso Brasileiro de Informática na Educação (WCBIE 2019)

\section{Resultados Esperados}

A partir da parceria firmada com uma escola estadual pública de ensino fundamental, espera-se que o aplicativo possa ser utilizado em sala de aula como como apoio ao ensino de ciências e de educação ambiental na cidade de Monte Carmelo/MG para promoção da conscientização do uso racional de recursos hídricos. A ideia é que o aplicativo não seja encarado do ponto de vista de punição aos infratores, mas, pelo contrário, de ensino e difusão das consequências do desperdício de água para a comunidade local e global por meio de notícias relacionadas com as categorias das denúncias.

Além de poder ser utilizado dentro de sala de aula, também poderá atuar como uma ferramenta gratuita para a comunidade local, dado que os estudantes poderão atuar como influenciadores de seus familiares e pessoas próximas.

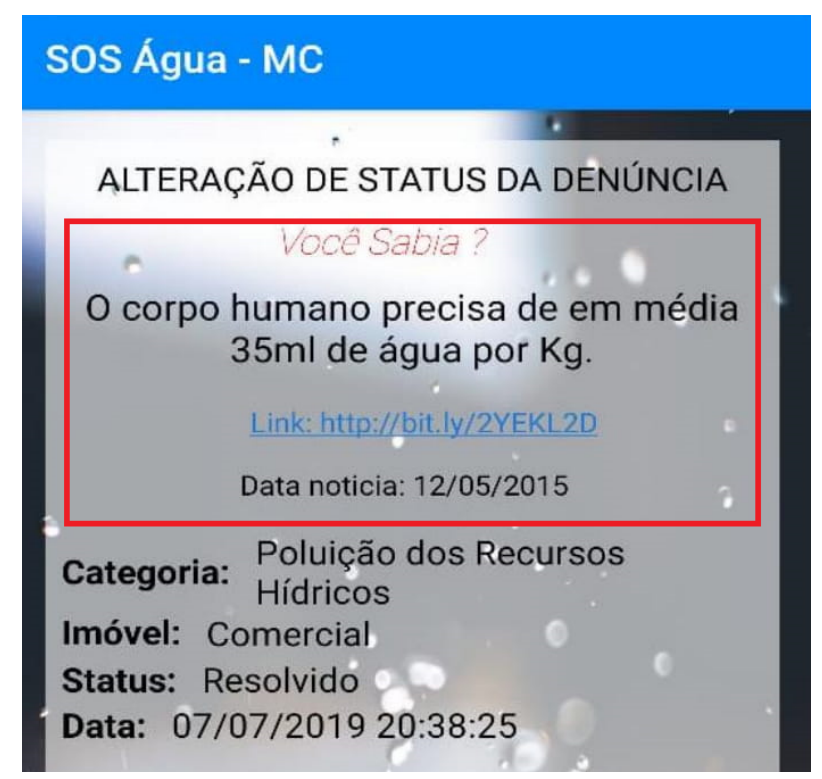

Figura 3. Tela de alteração do status da denúncia, com destaque para a funcionalidade "Você sabia?"

\section{Considerações finais}

A educação ambiental tem se tornado cada vez mais presente nas escolas do mundo, visando formar cidadãos mais conscientes com relação aos recursos naturais e a sustentabilidade. Em especial, o consumo irresponsável e a poluição dos recursos hídricos afetam diretamente a disponibilidade de água no Brasil e no mundo.

Dessa forma, estratégias e ferramentas digitais podem ser criadas a fim de conscientizar a população das consequências da má utilização e gestão dos recursos hídricos. Assim, este artigo apresentou um protótipo de um aplicativo Android para promoção do consumo consciente de água, por meio de denúncias anônimas efetuadas de forma colaborativa e categorizadas, e com a possibilidade de exibição de notícias da mídia relacionadas como recurso de aprendizagem.

Como trabalhos futuros, pretende-se avaliar a utilização do aplicativo com estudantes do ensino fundamental e professores, após a devida aprovação em Comitê de Ética em Pesquisa. No sistema Web será necessário criar uma identidade visual, tanto 
VIII Congresso Brasileiro de Informática na Educação (CBIE 2019)

Anais dos Workshops do VIII Congresso Brasileiro de Informática na Educação (WCBIE 2019)

para a parte administrativa que permite cadastrar parâmetros de sistema quanto para a parte pública. Com relação ao aplicativo móvel, implementações em outras linguagens possibilitarão a sua utilização em outras plataformas móveis. Além disso, pretende-se implementar novas funcionalidades, como listagens de denúncias por situação (pendentes e resolvidas) e buscas por categorias ou tipo de imóvel, por exemplo. Por fim, com logs de interação implementados, também será possível criar mecanismos para fornecer subsídios aos professores acerca da utilização do aplicativo.

\section{Agradecimentos}

Os autores agradecem o apoio da Universidade Federal de Uberlândia (FACOM/UFU e PROPP/UFU) e da Escola Estadual Melo Viana de Monte Carmelo/MG para a execução deste trabalho.

\section{Referências}

ANA (n.d.). Formulário de fiscalização e denúncias - Agência Nacional de Águas. Disponível em https://www.ana.gov.br/gestao-da-agua/outorga-efiscalizacao/fiscalizacao. Online; Acessado em 27/06/2018.

André, D. S., Macedo, D., e Estender, A. C. (2015). Conservação e uso racional da Água: Novoshábitos para evitar a escassez dos recursos hídricos e para a continuidade do bem finito. In XII Simpósio de Excelência em Gestão e Tecnologia.

Brondani, C. J. e Henzel, M. E. (2010). Análise sobre a conscientização ambiental em escolas da rede municipal de ensino. Revista Brasileira de Educação Ambiental (RevBEA), 5(1):37-44.

CGI.br (2018). Pesquisa sobre o uso das Tecnologias de Informação e Comunicação nos Domicílios Brasileiros - 2017. Technical report, Comitê Gestor da Internet no Brasil. Online; Disponível em https://www.cgi.br/publicacoes; Acessado em 28/05/2018.

DEMAE (n.d.). Formulário de denúncia anônima - Departamento Municipal de Água e Esgoto da Cidade de Monte Carmelo-MG . Disponível em http://www.dmae.montecarmelo.mg.gov.br/denuncie. Online; Acessado em 27/06/2018.

Freire, P. (1979). Conscientização. Teoria e prática da libertação: uma introdução ao pensamento de Paulo Freire. Cortez \& Moraes, São Paulo, Brasil.

Libâneo, J. C. (1994). Didática, capítulo “Os Métodos de Ensino”, páginas 140-176. Cortez Editora.

Monte Carmelo News (2017). Mananciais e reservatórios de monte carmelo já estão apresentando defasagem e escassez no volume de água. Disponível em https://www.montecarmelonews.com.br/mananciais-e-reservatorios-de-montecarmelo-ja-estao-apresentando-defasagem-e-escassez-no-volume-de-agua. Online; Acessado em 27/06/2018.

Nelson, R. A. R. R. (2017). Da importância dos recursos hídricos e a organização administrativa para sua proteção. Planeta Amazônia: Revista Internacional de Direito Ambiental e Políticas Públicas, 1(9):71-88. 
VIII Congresso Brasileiro de Informática na Educação (CBIE 2019)

Anais dos Workshops do VIII Congresso Brasileiro de Informática na Educação (WCBIE 2019)

ONU (2018). Sustainable Development Goal 6 - Synthesis Report 2018 on Water and Sanitation. Technical report, United Nations Publications. Online; Disponível em https://sustainabledevelopment.un.org/sdg6; Acessado em 15/06/2019.

Porto, M. F. M. M. (1998). Educação ambiental: conceitos básicos e instrumentos de ação. 2. In Educação ambiental: conceitos básicos e instrumentos de ação. 2. ed. FEAM.

Rodrigues, A. A., Silva, C. E., e Matsuoka, J. V. (2019). Avaliação do sistema de abastecimento de Água de monte carmelo/mg, a partir do plano municipal de saneamento básico. Gestão, Tecnologia e Ciências, 8(20):120-140.

Silva, F. C., Masetto, H. C. P., e Gomes, W. F. G. (2017). Água no século XXI - visão para unidade sucroenergética. Bioenergia em revista: diálogos, 7(2):98-119.

SNIS (2017). Diagnóstico dos Serviços de Água e Esgotos - 2017. Technical report, Sistema Nacional de Informações sobre Saneamento, Ministério do Desenvolvimento Regional. Online; Disponível em http://www.snis.gov.br/diagnostico-agua-e-esgotos; Acessado em 25/10/2019. 